\title{
OPINION
}

\section{Sperm crisis: what crisis?}

\author{
Eberhard Nieschlag' ${ }^{1}$ and Alexander Lerchl ${ }^{2}$
}

Asian Journal of Andrology (2013) 15, 184-186; doi:10.1038/aja.2012.90; published online 24 September 2012

or 20 years the so-called "sperm crisis"
caused unrest among the public as well as the scientific community. Studies precipitated by this virtual crisis have refuted its existence, but have also illuminated hitherto neglected aspects of male reproductive function and indicated a need for prospective, long-term monitoring systems.

Since 1992, the so-called 'sperm crisis' has lingered in the scientific literature and continues to agitate both media and the public. The basis for this sperm crisis is a publication from a Danish research group analysing 61 studies performed between 1938 and 1990 and concluding that sperm counts of otherwise healthy men had fallen drastically during the period of observation. ${ }^{1}$ It was even extrapolated that if the trend were to continue, sperm would totally disappear within the foreseeable future. This study, the 'Carlsen study' named after the first author, was and is heavily criticized regarding the study design, the heterogeneity of the investigated groups, the statistical evaluation, the nonstandardized methodology for semen analysis and varying times of abstinence. ${ }^{2-6}$ We do not want to repeat this criticism but just mention a few examples.

While internal and external quality control has been introduced more or less ubiquitously in the clinical chemical laboratory, the andrology lab remained a neglected area in this effort towards quality assurance. This made results obtained from different laboratories and even from the same laboratory difficult to compare, which became strikingly evident when the World Health Organization (WHO) started to perform worldwide multicentre trials for male contraception and

\footnotetext{
${ }^{1}$ Centre of Reproductive Medicine and Andrology, University of Münster, Münster 48129, Germany and ${ }^{2}$ School of Engineering and Science, Jacobs University Bremen, Bremen 28759, Germany

Correspondence: Professor E Nieschlag

(Eberhard.Nieschlag@ukmuenster.de)

Received: 18 July 2012; Revised: 26 July 2012; Accepted: 26 July 2012; Published online: 24 September 2012
}

for male infertility treatment. Awareness of quality control in the andrology laboratory was stimulated by the publication of the WHO Laboratory Manual for Semen Analysis (first edition 1980 and fifth edition $2010^{7}$ ). Under its influence and only over the last decade have programmes for external quality control been introduced. ${ }^{8}$ This has now progressed to the extent that for the first time in a multicentre study for male contraception, semen analysis has been partially centralized, thus avoiding interlaboratory variation. ${ }^{9}$ All these efforts have contributed to better comparability of semen parameters from different laboratories, but this type of standardisation certainly did not exist for the 61 papers reviewed in the Carlsen study.

In addition, pre-analytical conditions also play an important role in the results of semen analysis. To a large extent, the number of spermatozoa in the ejaculate is correlated positively with the duration of abstinence, ${ }^{10}$ as shown in Figure 1. By varying abstinence times, sperm concentrations may be manipulated. If abstinence time is not properly recorded, the interpretation of semen parameters will be incorrect. Although abstinence time appears to be a simple parameter easily determined, the recorded figures are quite unreliable. When questioned concerning the time of abstinence since the last ejaculation, patients' answers are often unreliable and the subject remains surrounded by taboos. In addition, actual sperm counts depend not only on the time of abstinence since the last ejaculation, but also on the frequency of ejaculations during the period preceding the actual investigation ${ }^{11}$ which makes the interpretation of results even more complicated. Changes in sexual behaviour and ejaculation frequency may have changed over the last 50 years and make historical comparisons notoriously difficult. Only recently and under the influence of the WHO manuals has more attention been paid to this variable, while abstinence time from older studies cannot be considered at face value.

The study by Carlsen et al. ${ }^{1}$ showed the alleged decline of sperm counts in a figure which contained, however, only half of the data as circles (31 vs. 61). Moreover, the circles' areas, reflecting the logarithm of the numbers of subjects per study, were wrong. ${ }^{2}$ The impression of the correct representation of the data is quite different from that of the original figure (Figure 2). The authors of the original study, despite agreeing that there was a 'deficiency' in the figure, classified this as being 'qualitatively unimportant' in their response. ${ }^{12}$ The comment and the reply were published in the same issue of British Medical Journal on 26 August 1995. It is disturbing to note that the same (and wrong) original figure was published again in the same year. ${ }^{13}$ Since that paper was accepted in September and published in December 1995, leaving ample time for corrections, one must conclude that the authors chose to ignore the suggested correction. Needless to say, the critical comment was not cited in that paper.

Another methodological problem was raised by Handelsman. ${ }^{14}$ He reanalysed the data from the Carlsen study by using the median instead of the mean values of the respective studies to account for the skewed, not normally distributed data. ${ }^{15}$ The results of this reanalysis showed no significant decline in sperm counts.

The shortcomings of the Carlsen study notwithstanding, it triggered 27 major studies taking ethnic and geographic differences into account. As a review by Fisch ${ }^{5}$ shows that 16 of these studies found no differences over time in sperm concentration, motility and morphology, five studies yielded ambiguous results and six studies demonstrated a decline in semen quality.

Despite the criticism and although the majority of ensuing studies could not confirm the Carlsen hypothesis, the sperm crisis 


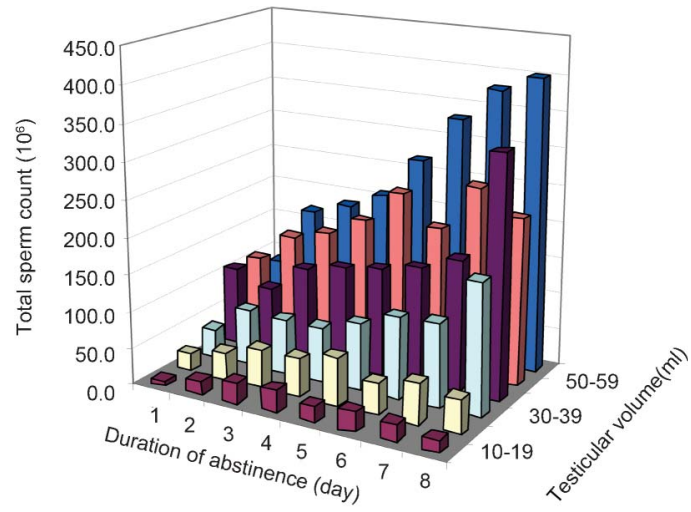

Figure 1 Dependence of abstinence time and testicular volume on total sperm counts. Reproduced with permission from Cooper. ${ }^{10}$

remained a never-ending topic. Although conclusive proof was lacking, a culprit was soon identified: the unhealthy environment. This popular fallacy led to large research grants for investigating possible connections between declining sperm numbers, as well as declining male fertility, with environmental toxins, and it remains a cornerstone of strategic plans for future andrological research. ${ }^{16}$ A testicular dysgenesis syndrome has been postulated as a unifying pathognomonic entity, ${ }^{17}$ although its epidemiological as well as endocrine basis has been questioned. ${ }^{18,19}$

Despite this research euphoria, some scientists postulated that this problem could not be resolved by retrospective or short-lived studies, but only by a prospective monitoring system encompassing longer time periods and including semen quality, as well as direct fertility measures such as time-to-pregnancy, in representative populations. ${ }^{20}$ This recommendation was also adopted by a working group of the (German) National Academy of Science on 'Future with Children' in order to resolve the question whether fertilitymale and/or female-is declining or not. ${ }^{21}$

Meanwhile the group in Copenhagen itself has provided results from such an ongoing prospective study, although in a somewhat
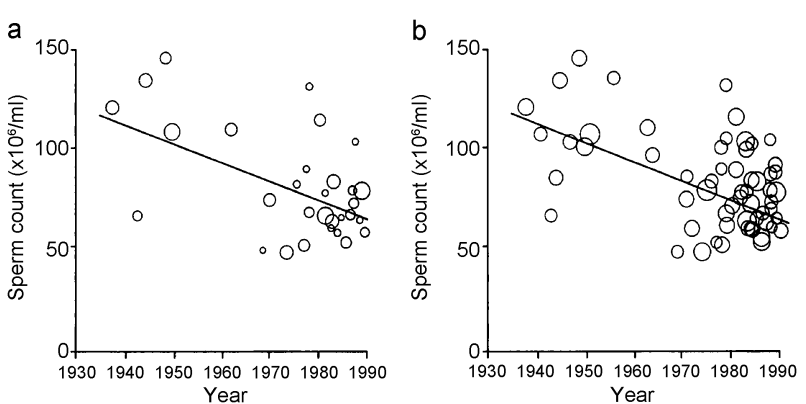

Figure 2 Original (a) and corrected (b) presentation of data from the Carlsen study. ${ }^{2}$ Reproduced with permission from British Medical Journal (BMJ). ${ }^{2}$

unusual fashion. At the European Congress of Endocrinology in Berlin in 2008, and again at the annual congress of the European Society of Human Reproduction and Endocrinology in Rome in 2010, Niels Jörgensen, the current head of the group in Copenhagen, presented evidence that they had collected semen data from draftees to the Danish army at annual intervals since 1996. Since then, 4867, on average 19-year-old, Danish men had been investigated. The sperm concentrations from the first 15 years ranged around a mean value of 40-45 million sperm per $\mathrm{ml}$, with a lowest value of 36 million in 2006 and a highest value of 50 million in 2007, without a significant decrease over time, but rather a tendency to increase (Figure 3).

Niels Jörgensen denied requests for those data. When asked when the data would be published, his answer was 'Not before two decades have been completed'. Considering the impact of these findings, this answer was surprising, as this group does not hesitate to publish data after shorter time intervals if they fit their concept, as a recent publication of declining sperm parameters in Finland over a period of only 8 years shows. ${ }^{22}$

It is surprising that these astonishing results were not first published by the investigators themselves, but rather by the Danish National Board of Health, which cosponsored the study. $^{23}$ Publication of the results was obviously considered to be in the public interest, but against the wish of the investigators, as Niels Skakkebek stated to a reporter from the New York Times ${ }^{24}$ and in a commentary in Epidemiology ${ }^{25}$ in 2011.

Be this as it may, by these means we have officially learned that the sperm concentrations of Danish young men did not deteriorate between 1996 and 2010. While the editor of Epidemiology regrets that the data had to be published in this unusual and indirect manner, he welcomes the fact that the data were made accessible to the public at all $^{26}$ and the well-known Danish epidemiologist, Jens Peter Bonde, was also surprised at his colleagues' behaviour. 27,28

Presumably giving in to pressure from the scientific community, the group in Copenhagen has given up its opposition to publish the data, and on 7 July 2012 a full paper summarising the findings to date appeared in British Medical Journal Open. ${ }^{29}$ Proper statistical evaluation of the data yielded results which are even more surprising than could be gleaned from the oral and online $e^{23}$ presentations mentioned above: not only did sperm concentrations and total sperm counts from the 4867 men fail to decrease over the 15-year period, they actually increased from 43 to 48 million $\mathrm{ml}^{-1}$ $(P=0.02)$ and 132 to 151 million $(P=0.001)$, respectively!

Instead of rejoicing that the previously predicted end of mankind, owing to disappearing spermatozoa, was no longer imminent, the apocalyptic investigators are still unhappy because only $23 \%$ of the investigated subjects had perfectly normal semen parameters. However, it has been known for many years-at least since normal volunteers have been recruited for trials in hormonal male contraception $^{30}$ - that only a fraction of men in the general population fulfill WHO criteria for normal semen parameters. Acknowledging this phenomenon, the fifth edition of the WHO Laboratory $\mathrm{Manual}^{7}$ shifted from consensus values in the previous editions to evidence-based reference values obtained from fertile men. These are quite different from the previous 'normal values'. ${ }^{31}$ Had Jørgensen et al. ${ }^{29}$ referred to these new reference values, their analysis would have appeared quite different. Moreover, the WHO guidelines for semen analysis are accorded little respect, as the authors state that they performed semen analysis in their volunteers following the fifth edition of the 


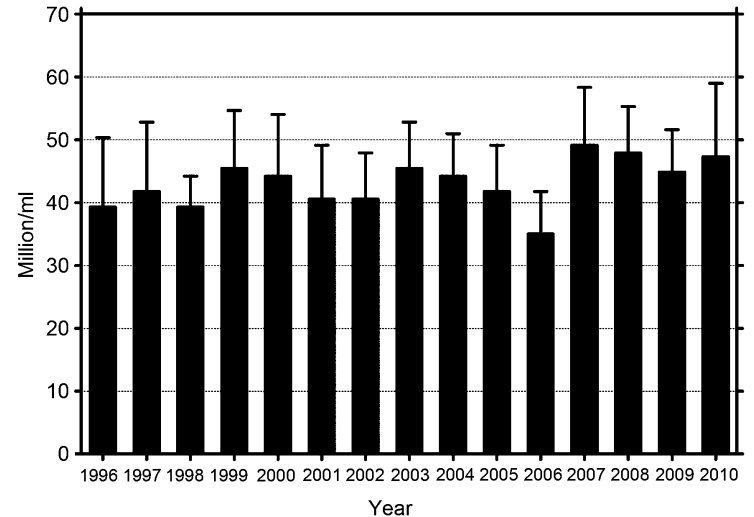

Figure 3 Mean sperm concentration of 5000 Danish draftees from 1996 to $2010^{23}$ (16\%-30\% of all Danish draftees, i.e., 300 men per year, 18 years old).

WHO Manual when in fact the investigations were performed up to 15 years before the appearance of this edition in 2010; there are considerable methodological differences between the fifth and previous editions.

Furthermore, Jørgensen et al. ${ }^{29}$ compare current results with those from a doctoral dissertation on semen parameters of partners from infertile couples from Copenhagen from 1939 to $1943 .^{32}$ Once again, they find a decrease from then to today. However, by doing so, they are committing the same error as in the Carlsen study concerning historical comparisons of semen parameters. For example, Hammen ${ }^{32}$ used an alcoholic diluent for counting spermatozoa, which may evaporate and thus artificially increase the sperm concentration, and is therefore considered obsolete today; he also counted tailless sperm heads as spermatozoa, which is again no longer the case, and this increases the number of spermatozoa counted. In addition, a direct comparison of different collectives-infertile men vs. draftees-is highly questionable. Finally, they again ignore the importance of abstinence time, as the recent subjects were asked to observe an abstinence time of at least $48 \mathrm{~h}$ while the men from infertile couples 70 years ago were asked for at least $72 \mathrm{~h}$ the possible impact being discussed above!

In conclusion, the new data ${ }^{29}$ covering a 15 -year period cannot definitively answer the question of a secular trend. And while they provide no reason for our continuing to believe in decreasing sperm counts and in the 'sperm crisis', they offer striking evidence that only prospective studies using standardized methodology will yield an adequate basis for conclusions on semen parameters, fertility and infertility. ${ }^{6,20,33}$ Scientists' recommendations to politicians, e.g., on questions on human reproduction will only be accepted as reliable if they are based on exact and verifiable facts that will not collapse within a few years like a house of cards. The Carlsen study obviously led us down the wrong path. There remains the dubious consolation that this study has greatly popularized the field of andrology and has, for the first time, directed substantial financial support towards andrological research. Finally, it must be acknowledged that the research group that led us down the wrong path also demonstrated how we can get back on the proper research track.

\section{COMPETING FINANCIAL INTERESTS}

The authors declare that they have no competing financial interests in relation to this paper.

1 Carlsen E, Giwercman A, Keiding N, Skakkebaek NE. Evidence for decreasing quality of semen during past 50 years. BMJ 1992; 305: 609-13.

2 Lerchl A. Evidence for decreasing quality of sperm. Presentation of data on sperm concentration was flawed. BMJ 1995; 311: 569-70.

3 Lerchl A, Nieschlag E. Decreasing sperm counts? A critical (re)view. Exp Clin Endocrinol Diabetes 1996; 104: 301-7.

4 Lerchl A, Nieschlag E. Declining sperm counts in European men-fact or fiction? Andrologia 1996; 28: 305-6.

5 Fisch $H$. Declining worldwide sperm counts: disproving a myth. Urol Clin North Am 2008; 35: 137-46.

$6 \quad$ Nieschlag $\mathrm{E}$, te Velde $\mathrm{E}$. Why have birth rates dropped? For medical reasons? J Reproduktionsmed Endokrinol 2010; 7: 403-6.

7 World Health Organization. WHO Laboratory Manual for the Examination and Processing of Human Semen, 5th ed. Geneva: World Health Organization; 2010.

8 Mallidis C, Cooper TG, Hellenkemper B, Lablans M, Ückert $\mathrm{F}$ et al. Ten years experience with an external quality control programme for semen analysis. Fertil Steril; e-pub ahead of print 24 May 2012; doi:10.1016/j.fertnstert.2012.05.006.

9 Mommers E, Kersemaekers WM, Elliesen J, Kepers M, Apter $\mathrm{D}$ et al. Male hormonal contraception: a doubleblind, placebo-controlled study. J Clin Endocrinol Metab 2008; 93: 2572-80.

10 Cooper TG. Semen analysis. In: Nieschlag E, Behre $\mathrm{HM}$, Nieschlag S, editors. Andrology: Male
Reproductive Health and Dysfunction, 3rd ed. Heidelberg: Springer; 2010. p125-54.

11 Cooper TG, Keck C, Oberdieck U, Nieschlag E. Effects of multiple ejaculations after extended periods of sexual abstinence on total, motile and normal sperm numbers, as well as accessory gland secretions, from healthy normal and oligozoospermic men. Hum Reprod 1993; 8: 1251-8.

12 Keiding N, Skakkebaek NE. Authors' reply. BMJ 1995; 311: 570.

13 Jensen TK, Toppari J, Keiding N, Skakkebaek NE. Do environmental estrogens contribute to the decline in male reproductive health? Clin Chem 1995; 41: 1896-901.

14 Handelsman DJ. Estrogens and falling sperm counts. Reprod Fert Dev 2001; 13: 317-24.

15 Bromwich P, Cohen J, Stewart I, Walker A. Decline in sperm counts: an artefact of changed reference range of 'normal'? BMJ 1994; 309: 19-22.

16 EU Strategic research plan 2010. Male reproductive health: its impact in relation to general well-being and low European fertility rates. European Science Foundation: Strasbourg Cedex, France, September 2010. European Science Foundation (ESF) Science Policy Briefing 40.

17 Wohlfahrt-Veje C, Main KM, Skakkebaek NE. Testicular dysgenesis syndrome: foetal origin of adult reproductive problems. Clin Endocrinol (Oxf) 2009; 71: 459-65.

18 Akre 0, Richiardi L. Does a testicular dysgenesis syndrome exist? Hum Reprod 2009; 24: 2053-60.

19 Fisch H, Hyun G, Hensle TW. Rising hypospadias rates: disproving a myth. J Pediatr Urol 2010; 6: 37-9.

20 te Velde E, Burdorf A, Nieschlag E, Eijkemans R, Kremer JA et al. Is human fecundity declining in Western countries? Why we will never know. Hum Reprod 2010; 25: 1348-53.

21 Stock G, Bertram H, Fürnkranz-Prskawetz A, Holzgreve W, Kohli M, Staudinger M (eds). Zukunft mit Kindern. München: Berlin-Brandenburgische Akademie der Wissenschaften, Campus-Verlag; 2012.

22 Jörgensen N, Vierula M, Jacobsen R, Pukkala E, Perheentupa $A$ et al. Recent adverse trends in semen quality and testis cancer incidence among Finnish men. Int J Androl 2010; 36: e37-48.

23 http://www.sst.dk/ /media/Sundhed\%20og\%20foreby ggelse/Seksualitet/Notater/NotatSaedkvalitetPubertet. ashx (25 March 2011; last accessed 17 July 2012).

24 Kolata G. In: update on sperm, data show no decline. New York Times 6 June 2011

25 Skakkebaek NE, Andersson AM, Juul A, Jensen TK, Almstrup $\mathrm{K}$ et al. Commentary: sperm counts, data responsibility, and good scientific practice. Epidemiology 2011; 22: 620-1.

26 Wilcox AJ. On sperm counts and data responsibility. Epidemiology 2011; 22: 615-6.

27 Bonde JE, Ramlau-Hansen $\mathrm{CH}$, Olsen J. Trends in sperm counts: the saga continues. Epidemiology 2011; 22: 617-9.

28 Bonde JP, Olsen J, Ramlau-Hansen CH. Danish sperm counts (Cont'd.). Epdidemiology 2011; 22: 878.

29 Jørgensen $N$, Joensen UN, Jensen TK, Jensen MB, Almstrup $\mathrm{K}$ et al. Human semen quality in the new millennium: a prospective cross-sectional population-based study of 4867 men. BMJ Open 2012; 2: e000990. doi: 10.1136/bmjopen-2012000990.

30 Lemcke B, Behre HM, Nieschlag E. Frequently subnormal semen profiles of normal volunteers recruited over 17 years. Int J Androl 1997; 20: 144-52.

31 Cooper TG, Noonan E, von Eckardstein S, Auger J, Baker HW et al. World Health Organization reference values for human semen characteristics. Hum Reprod Update 2010; 16: 231-45.

32 Hammen R. Studies on impaired fertility in man with special reference to the male. Acta Obstet Gynecol Scand 1944; 24 (Suppl 3): 1-205.

33 Olsen J, Rachootin P. Monitoring fecundity over time-if we do it, then let's do it right. Am J Epidemiol 2003; 157: 94-7. 